\title{
THE INSULIN SENSITIVITY OF PATIENTS WITH DIABETES MELLITUS 1,2
}

\author{
BY POUL KIRKETERP
}

(From the Aarhus County Hospital, Denmark)

(Submitted for publication April 8, 1949; accepted, September 28, 1950)

Utilizing a specific technique which they developed, Himsworth and Kerr (1) studied a group of 24 patients with diabetes mellitus and concluded that such patients can be classified into two distinct groups, one of which was insulin sensitive and the other insulin insensitive. DeWesselow and Griffiths (2) using a modification of Himsworth's technique, found no sharp division between sensitive and insensitive types but rather a general distribution of responses similar to that of a normal group of subjects; the extreme incidence of sensitivity and insensitivity merging into a central group showed a normal response. In referring to the latter study, Himsworth (3) postulated that the difference between the two sets of observations could be attributed to the technique used by DeWesselow and Griffiths. Since we could find no other report concerning this problem, we deemed it important to repeat the experiments of Himsworth and Kerr. Towards that end we made every effort to duplicate their conditions and procedures.

\section{METHOD}

Fifty patients (21 men and 29 women) with diabetes mellitus, ranging in age from 12 to 77 , were studied. No patients with liver disease, infections, or any manifest abnormality of the thyroid, pituitary, or adrenal function were included. Patients with diabetes of every degree of severity were included. The mildest severity of disease was that of Patient 34, an obese woman, aged 55, with no subjective symptoms of diabetes, whose glycosuria was discovered accidentally. Although her glycosuria disappeared when she was on a carbohydrate-poor diet, her fasting blood sugar remained elevated (120-140 mgm. \%). No subject in whom the only manifestation of diabetes mellitus was an abnormal glucose tolerance curve, was included in this study.

All the subjects were in an optimal state of regulation at the time of the study, and for at least four days before the test had been eating a diet containing 1,800 to 2,100 calories which included 125 to 175 grams of carbohydrate.

1 Presented before the Scandinavian Congress for Internal Medicine, June, 1948.

2 Aided by a grant from Nordisk Insulin Foundation.
In no case was protamine-zinc insulin given during the 24 hours, or any form of insulin during the 12 hours, preceding the test. During the test periods, the fasting subjects were kept completely at rest. Thirty grams of glucose per square meter of body surface, dissolved in $\mathbf{3 0 0}$ cc. of water were given orally and the blood glucose concentration determined by the Hagedorn-Jensen method at $5,10,15,20,25,30,45$ and 60 minutes after the glucose ingestion. Forty-eight hours later, the same quantity of glucose was administered orally and simultaneously an intravenous injection of five units of insulin (Danish Leo insulin) per square meter of body surface was given. Samples of blood for glucose determination were drawn at the same intervals as in the previous test. Every effort has been made to utilize the identical experimental technique, and even the same insulin preparation which was employed by Himsworth and Kerr.

\section{RESULTS}

The data were analyzed in the manner described by Himsworth and Kerr. Thus, the area included by the glucose tolerance curve above the resting level was measured by means of a planimeter and was designed as " $G$ " (glucose area); the area enclosed between the glucose tolerance curve

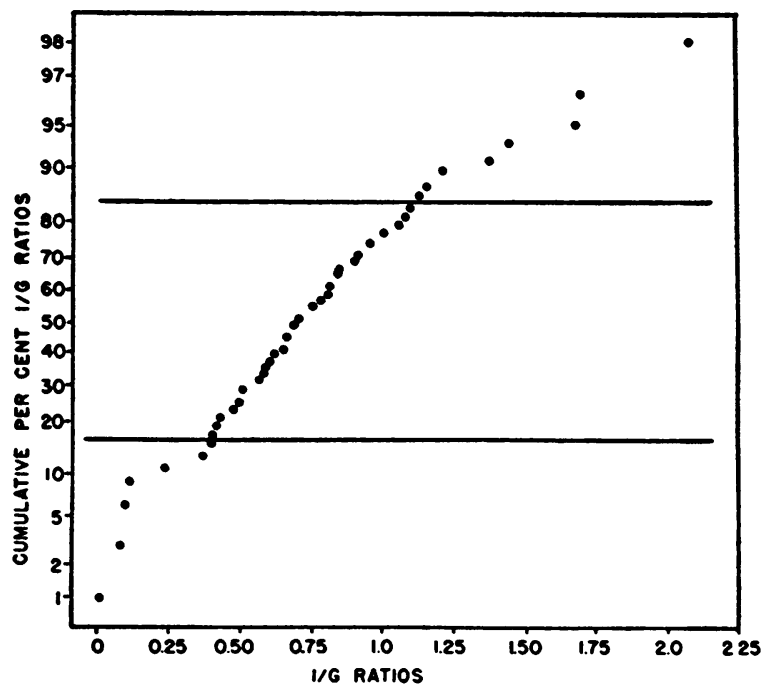

Fig. 1. Distribution of I/G Ratios Plotted as the Cumulative Percentage on Probability Paper 


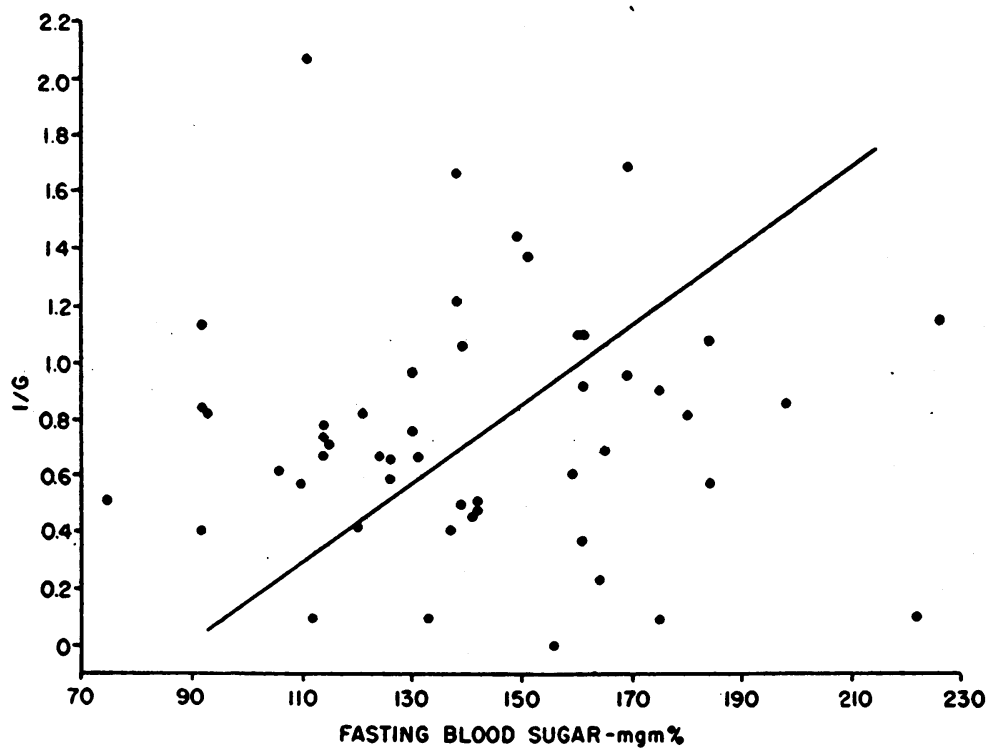

Fig. 2. Relation between the Fasting Blood Sugar Concentration AND THE Sensitivity to INSULIN

and the insulin-glucose curve was designated as "I" (insulin area). The "I/G" ratio was computed as the ratio between the area enclosed by the insulin curve and the corresponding area enclosed by the glucose curve.

Insulin sensitivity as expressed by the $\mathrm{I} / \mathrm{G}$ ratio varied markedly, ranging from 0.096 to 2.084 (Figure 1). The distribution of the values expressing insulin sensitivity in this manner is such as to make it probable that about $90 \%$ of the patients examined comprise a single group which is

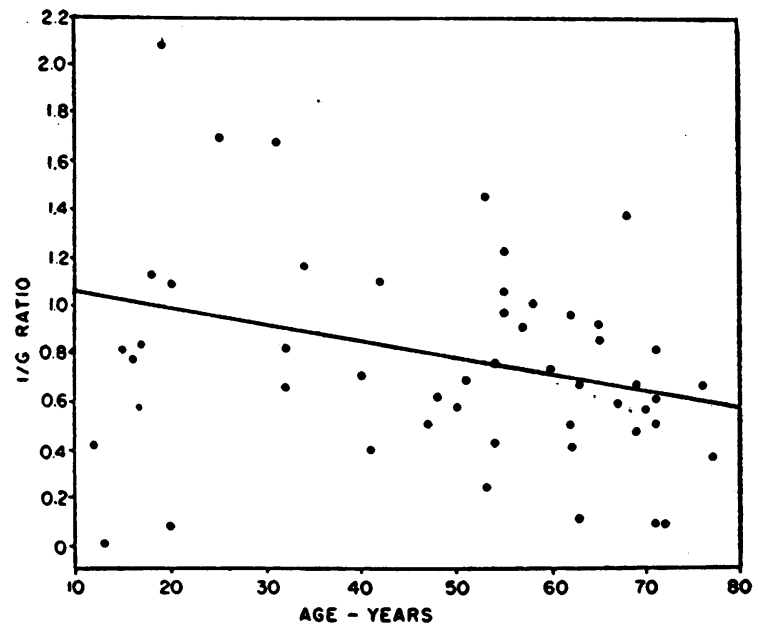

Fig. 3. Relation between Insulin Sensitivity and the Age of the Subjects distributed normally. That the $\mathrm{I} / \mathrm{G}$ ratio varied directly with the effectiveness of the insulin is suggested by Figure 2 .

The data illustrated in Figure 3 reveal that the $\mathrm{I} / \mathrm{G}$ ratio is not significantly influenced by the age of the subject. Further, similar analyses indicate that neither the duration of the metabolic disorder (Figure 4) nor the fasting blood sugar (Figure 2)

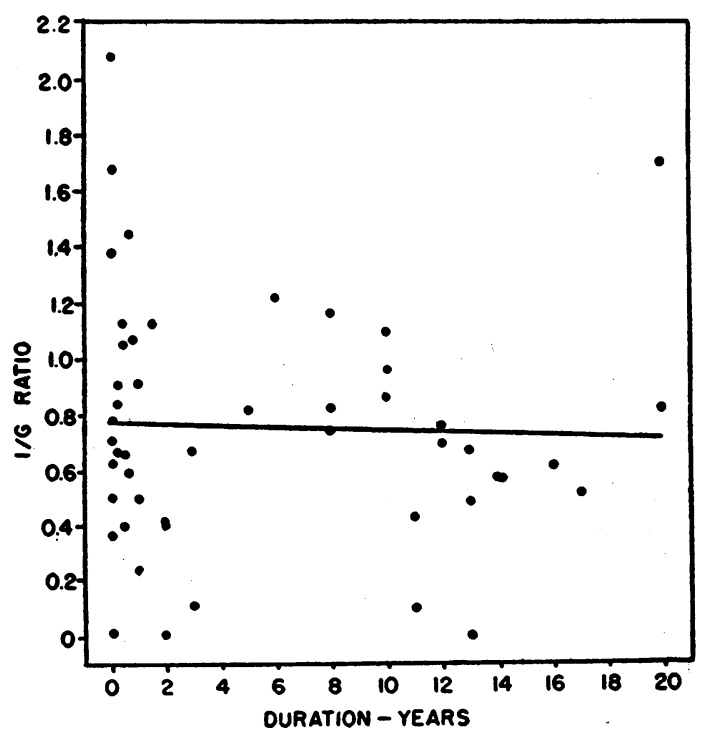

Fig. 4. Relation between Insulin Senstivity and the Duration of the Diabetes Melitus 
exerted any significant effect on the sensitivity to insulin as determined by the $\mathrm{I} / \mathrm{G}$ ratio.

\section{SUMMARY}

The results obtained in this study differ quite distinctly from those reported by Himsworth and Kerr, in that we were unable to obtain two distinct groups of patients with diabetes insofar as insulin sensitivity was concerned. Instead we have found that the insulin sensitivities of these subjects as expressed by the $\mathrm{I} / \mathrm{G}$ ratio tend to concentrate about a mean value of 0.702 . Only $16(32 \%)$ of the patients had ratios greater than 0.9 , a value which was exceeded by all of the so-called insulin sensitive patients reported by Himsworth and Kerr.

\section{CONCLUSION}

1. The insulin sensitivity of 50 patients with diabetes mellitus was studied under carefully standardized conditions, and the I/G ratio determined according to the method of Himsworth and Kerr.

2. No distinct separation of the patients into insulin-sensitive and insulin-insensitive categories could be observed.

\section{ACKNOWLEDGMENT}

The author gratefully acknowledges the aid of Dr. S. Loube of Washington, D. C., in the preparation of the manuscript.

\section{BIBLIOGRAPHY}

1. Himsworth, H. P., and Kerr, R. B., Insulin-sensitive and insulin-insensitive types of diabetes mellitus. Clin. Sc., 1939, 4, 119.

2. DeWesselow, O. L. V., and Griffiths, W. J., Insulin resistance in diabetes mellitus and the effect of dietary carbohydrate. Quart. J. Med., 1938, 7, 17.

3. Himsworth, H. P., The mechanism of diabetes mellitus. Lancet, 1939, $2,1$. 